\title{
NUMERICAL MODELLING OF STRUCTURES WITH UNCERTAINTIES
}

\begin{abstract}
The nature of environmental interactions, as well as large dimensions and complex structure of marine offshore objects, make designing, building and operation of these objects a great challenge. This is the reason why a vast majority of investment cases of this type include structural analysis, performed using scaled laboratory models and complemented by extended computer simulations. The present paper focuses on FEM modelling of the offshore wind turbine supporting structure. Then problem is studied using the modal analysis, sensitivity analysis, as well as the design of experiment (DOE) and response surface model (RSM) methods. The results of modal analysis based simulations were used for assessing the quality of the FEM model against the data measured during the experimental modal analysis of the scaled laboratory model for different support conditions. The sensitivity analysis, in turn, has provided opportunities for assessing the effect of individual FEM model parameters on the dynamic response of the examined supporting structure. The DOE and RSM methods allowed to determine the effect of model parameter changes on the supporting structure response.
\end{abstract}

Keywords: Wind Turbine, Offshore, FEA, Modal Analysis, Dynamic Coupling, Sensitivity Analysis, Design of Experiment, Response Surface Method.

\section{INTRODUCTION}

The use of numerical techniques [1], [2], [3], [4], [5], in combination with the development of measurement techniques [6], [7], [8], [9], [10], [11], and the use of modern hardware [12], [13], provide opportunities to analyse more and more complex physical phenomena. Of special importance here is the progress in techniques used to create virtual models of real structures which model their behaviour in the best possible way [14], [15], [16], [17]. For the offshore structures, especially those founded on the seabed, the uncertainty of geo-mechanical parameters of the seabed [18], [19] and various dynamic couplings, which are difficult to quantify, are the sources of serious complications when creating a numerical model. In this paper, use is made of experimental and numerical modal analysis techniques [20] to develop modal models, the correlation of which will allow to identify parameters of the real object. An attempt has also been made, with the aid of the design of experiment (DOS) and response surface model (RSM) methods [21], to assess the effect of unknown dynamic coupling on the structural response of the offshore wind turbine supporting structure.

\section{EXAMINED OBJECT}

The examined object is the scaled (1:40) laboratory model of the offshore wind turbine supporting structure in tripod configuration. The model is made of aluminium. Physical properties of aluminium assumed in the simulations are the following: Young's modulus (E) - $70 \mathrm{GPa}$, Poisson's ratio $(v)$ -0.33 , density $(\rho)-2750 \mathrm{~kg} / \mathrm{m}^{3}$. The nominal values of the geometrical parameters are given in Fig. 1. The height of the laboratory model is $1,885 \mathrm{~m}$, and its mass is $32,5 \mathrm{~kg}$. 


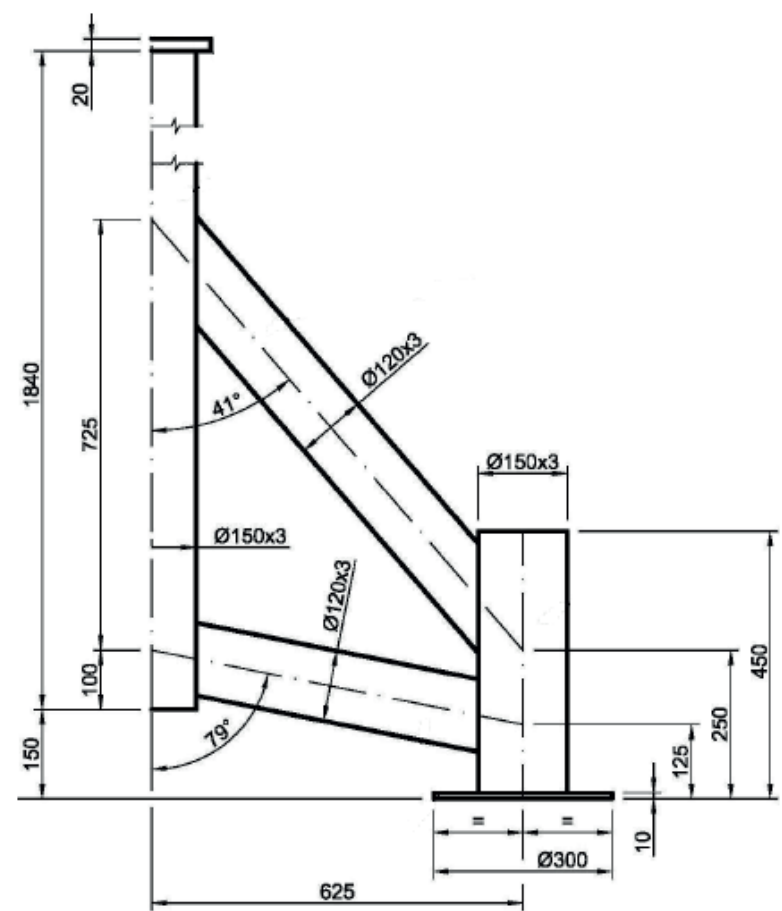

Fig. 1. Geometrical parameters of the supporting structure.

Three support cases have been analysed: (1) free-free support configuration, with good correlation observed [2]; (2) model suspended on an elastic rod, and (3) model founded on rubber blocks. The boundary conditions for the real object are shown in Fig. 2.

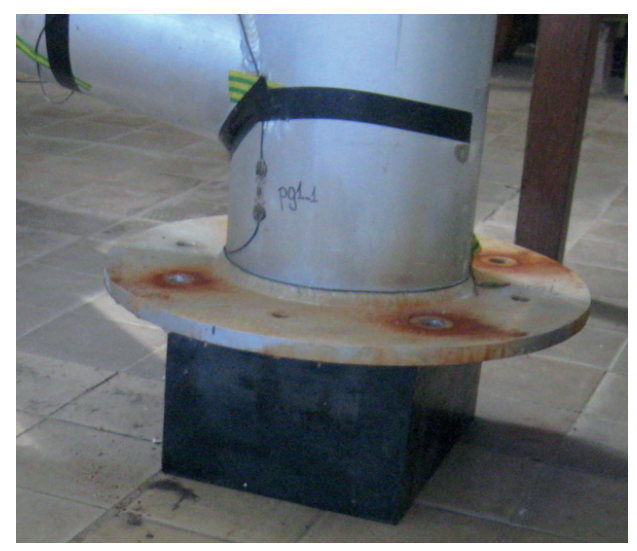

Fig. 2. Conditions of tripod foundation on rubber blocks.

\section{EXPERIMENTAL TESTS}

The experimental modal analysis was based on acceleration measurements at 61 points. 11 accelerometers were mounted on the central column (TS), and 5 accelerometers on each remaining supporting structure element (PG, UB, LB). Electromagnetic inductors fixed to the structure at two points (marked red in Fig. 2) were used to generate as many vibration modes as possible.

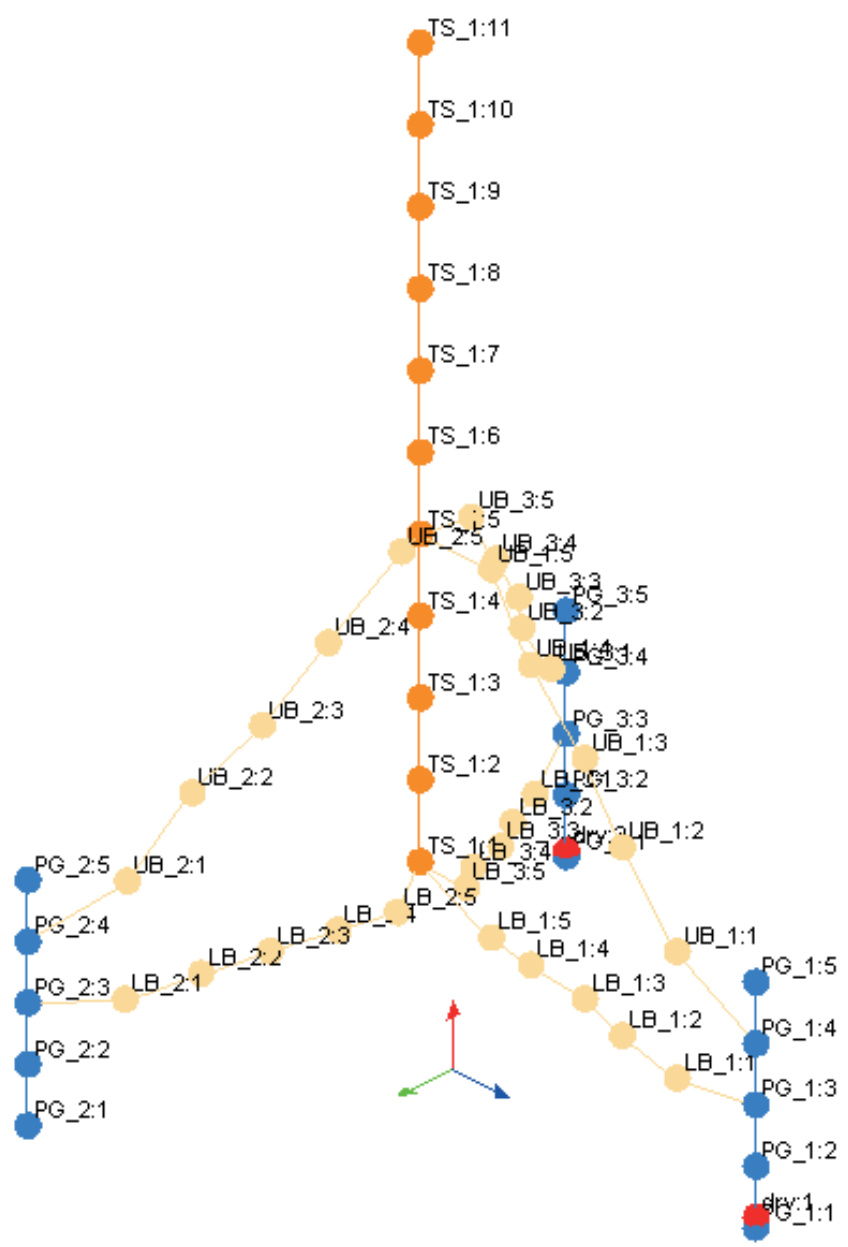

Fig. 2. Acceleration sensor locations.

After completing the measuring campaign, natural vibration modes of the structure were identified within the range from 66 to $280 \mathrm{~Hz}$ for the free-free support conditions, and within 42 to $310 \mathrm{~Hz}$ for the structure founded on rubber blocks. The first ten modes and the natural mode of tripod vibrations were taken into consideration in the further analysis. A more detailed description of the measuring campaign and the analysis of the obtained results can be found in [1] and [2].

\section{FINITE ELEMENT METHOD}

Due to the thin-walled structure of the real object, the same grid topology of two-dimensional finite plate elements was used in both support cases. Initially, the structure was attributed with nominal values of material and geometrical parameters. Despite the symmetry of the structure, each grid component (pile guide, upper and lower flange, and central column), was attributed with individual ES properties, which allowed to control the order of appearance of natural vibration modes [1]. The only difference between the numerical models with respect to support conditions for free-free support configuration and model foundation on rubber blocks was 
the use of elastic elements with three degrees of freedom (rotational stiffness was omitted) to model tripod interaction with the rubber blocks, Fig.3.

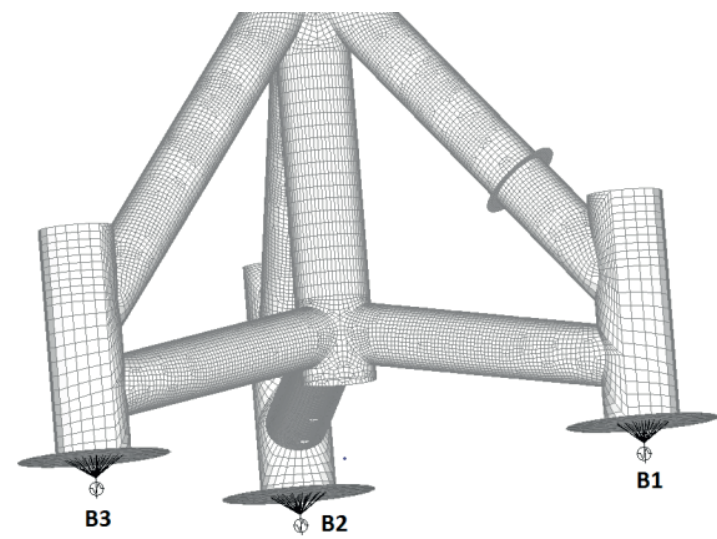

Fig. 3. Elastic elements modelling the stiffness of rubber blocks.

It has been assumed that within the tested range the rubber block material has a linear-elastic characteristic. Applying the force method to the rubber blocks, their stiffness was assessed as equal to $19700 \mathrm{~N} / \mathrm{m}$ along the vertical axis, and to $1000 \mathrm{~N} / \mathrm{m}$ along the transverse axes.

Correlation and tuning of experimental and simulated models

To assess the quality of the FEM model, its correlation with the experimental modal model, treated as the accurate reference model, was estimated. The tuning process made use of the modal assurance criterion (MAC) matrix, calculated from the following formula:

$$
{ }_{M A C} C_{\text {TestFE }}=\frac{\left[\Phi_{\text {Test }}^{T} \cdot \Phi_{E}\right]^{2}}{\left[\Phi_{\text {Test }}^{T} \cdot \Phi_{\text {Test }}\right]\left[\Phi_{E}^{T} \cdot \Phi_{E}\right]}
$$

where $\Phi$ is the natural vibration mode vector. The MAC matrix represents linear relationship between vectors and takes values from within the interval $\langle 0,1>$, where 1 means full linear relationship between the vectors, while 0 means that the vectors are fully linearly independent. Due to the difference in model sizes, the FEM model was to be reduced to the number of nodes in the experimental model, using the SEREP (System Equivalent Reduction Expansion Process) method for instance. Moreover, the degrees of freedom which were not measured in the experiment, i.e. the rotational degrees of freedom in this case, were also to be excluded from the FEM model.

The tuning process was conducted in the iterative optimisation loop. During these calculations, the values of the FEM model parameters were changed within an assumed range. The goal of the optimisation was to reach the maximum value of MAC, at simultaneous minimisation of differences between natural vibration frequency values in the modal FEM model and the experimental model. The quantitative effect of an individual FEM model parameter on the natural vibration frequency was assessed by analysing local sensitivity, i.e. the effect of changing a single parameter at fixed values of the remaining parameters, according to the formulas:

$$
\begin{gathered}
\frac{\partial \omega_{i}}{\partial q}=\frac{1}{2 m_{i}}[\Phi]_{i}^{T}\left(-\omega_{i} \frac{\partial[M]}{\partial q}+\frac{1}{\omega_{i}} \frac{\partial[K]}{\partial q}\right)[\Phi]_{i} \\
\frac{\partial[\Phi]_{i}}{\partial q}=-\frac{1}{2 m_{i}}[\Phi]_{i}^{T} \frac{\partial[M]}{\partial q}[\Phi]_{i}[\Phi]_{i}+\sum \frac{1}{\omega_{\mathrm{i}}^{2}-\omega_{\mathrm{k}}^{2}} \frac{1}{m_{\mathrm{k}}}[\Phi]_{\mathrm{k}}^{\mathrm{T}}\left(-\omega_{\mathrm{i}}^{2} \frac{\partial[\mathrm{M}]}{\partial \mathrm{q}}+\frac{\partial[\mathrm{K}]}{\partial \mathrm{q}}\right)[\Phi]_{\mathrm{i}}[\Phi]_{\mathrm{k}}
\end{gathered}
$$

Equation (2) describes the sensitivity of the eigenvalue, while Equation (3) - the sensitivity of the natural vibration mode vector. $[\mathrm{M}]$ is the inertia matrix, $[\mathrm{K}]$ is the stiffness matrix, $m$ is the modal mass, $\Phi$ is the resonance frequency, and $\mathrm{q}$ is the analysed parameter. Since the sensitivity is a function of model parameters, it had to be calculated in the iteration loop. The tuning process is schematically shown in Fig. 4.

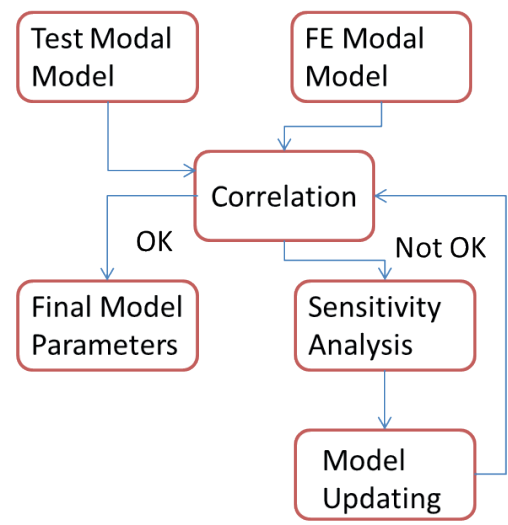

Fig. 4. Block diagram of the FEM model tuning process.

For the tripod in free-free support configuration, the initial MAC matrix (for nominal parameters of the FEM model) is shown in Fig. 5, while the corresponding relative errors of natural vibration frequency values are collated in Tab. 1.

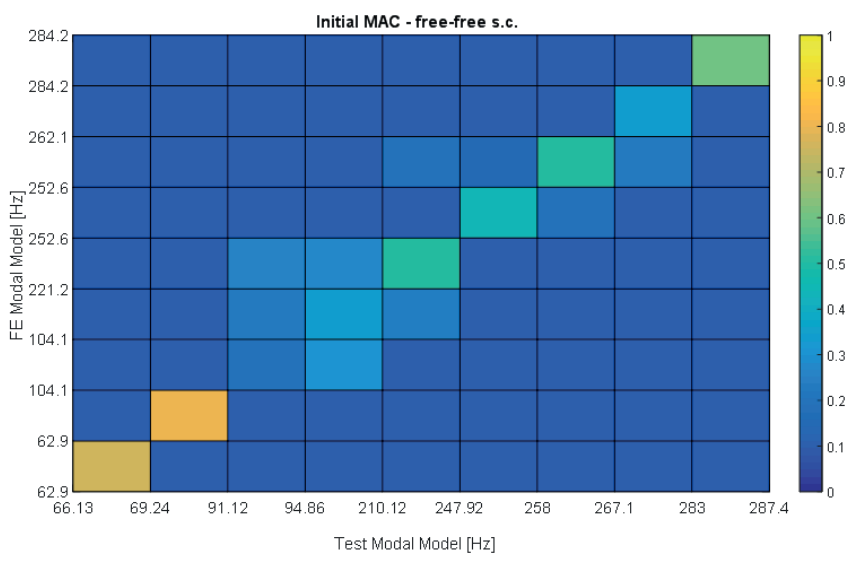

Fig. 5. MAC matrix for free-free support configuration and nominal FEM model parameters. 
Table 1. Relative errors of natural vibration frequency values for nominal FEM model parameters.

\begin{tabular}{|c|c|c|c|}
\hline & FE $\omega[\mathbf{H z}]$ & EMA $\boldsymbol{\omega}\{\mathbf{H z}]$ & error [\%] \\
\hline 1 & 62.9 & 66.13 & 4.9 \\
\hline 2 & 62.9 & 69.24 & 9.15 \\
\hline 3 & 104.1 & 91.12 & 14.24 \\
\hline 4 & 104.1 & 94.86 & 9.74 \\
\hline 5 & 221.2 & 210.12 & 5.27 \\
\hline 6 & 252.6 & 247.92 & 1.88 \\
\hline 7 & 252.6 & 258 & 2.09 \\
\hline 8 & 262.1 & 267.1 & 1.87 \\
\hline 9 & 284.2 & 283 & 0.42 \\
\hline 10 & 284.2 & 287.4 & 1.11 \\
\hline
\end{tabular}

The best MAC result obtained in the iterative calculation process is shown in Fig. 6, while the corresponding relative errors of natural vibration frequency values are collated in Tab. 2. The optimisation was performed using only the wall thickness values of the tripod components, at possible thickness changes assumed within $+/-3 \%$ of the nominal value. The calculated thicknesses of tripod walls, along with relative percentage changes in relation to the nominal parameters, are shown in Tab. 3.

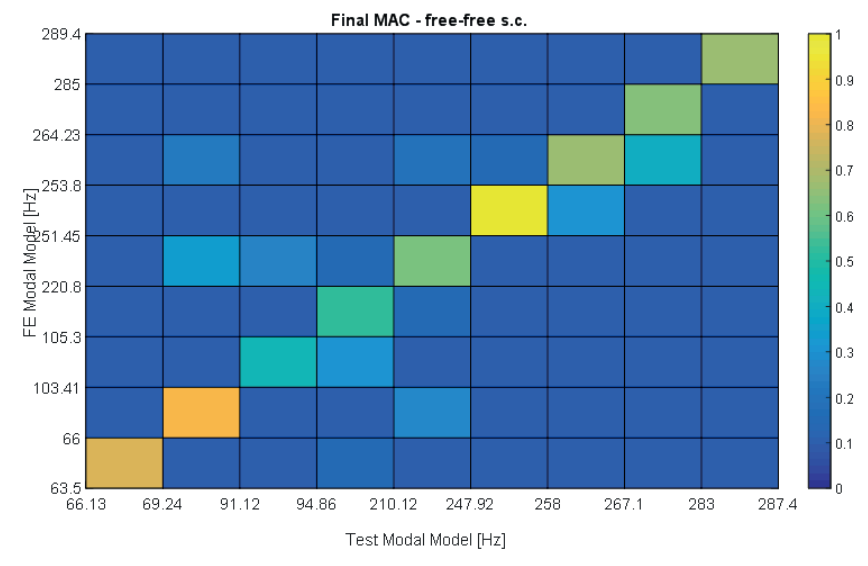

Fig. 6. Best MAC result obtained in the iteration process.

Table 2. Relative errors of natural vibration frequencies of the tuned FEM model.

\begin{tabular}{|c|c|c|c|}
\hline & FE $\omega[\mathrm{Hz}]$ & EMA $\omega[\mathrm{Hz}]$ & error [\%] \\
\hline 1 & 63.5 & 66.13 & 4.1 \\
\hline 2 & 66 & 69.24 & 4.9 \\
\hline 3 & 103.41 & 91.12 & 11.8 \\
\hline 4 & 105.3 & 94.86 & 9.9 \\
\hline 5 & 220.8 & 210.12 & 4.8 \\
\hline 6 & 251.45 & 247.92 & 1.4 \\
\hline 7 & 253.8 & 258 & 1.6 \\
\hline 8 & 264.23 & 267.1 & 1.08 \\
\hline 9 & 285 & 283 & 0.70 \\
\hline 10 & 289.4 & 287.4 & 0.69 \\
\hline
\end{tabular}

Table 3. Final set of FEM model parameters (wall thicknesses of tripod components).

\begin{tabular}{|c|c|c|}
\hline & gr. $[\mathrm{mm}]$ & diff. [\%] \\
\hline TS & 3.01 & 0.33 \\
\hline UB_1 & 3.09 & 3 \\
\hline UB_2 & 2.99 & 0.33 \\
\hline UB_3 & 3.008 & 0.27 \\
\hline LB_1 & 2.995 & 0.17 \\
\hline LB_2 & 2.998 & 0.067 \\
\hline LB_3 & 2.998 & 0.067 \\
\hline PG_1 & 3.0075 & 0.25 \\
\hline PG_2 & 3.02 & 0.67 \\
\hline PG_3 & 3.015 & 0.5 \\
\hline
\end{tabular}

In the case of tuning the model of supporting structure founded on rubber blocks, it was again the wall thicknesses which were used as tuned parameters, with their values changing within $+/-3 \%$ of the nominal value. But this time the set of optimised parameters was extended by the stiffnesses of the rubber blocks, with their permissible variability assumed within $+/-40 \%$ of the assessed stiffness values. The MAC matrix for nominal values of parameters for the tripod founded on rubber blocks is shown in Fig. 7.

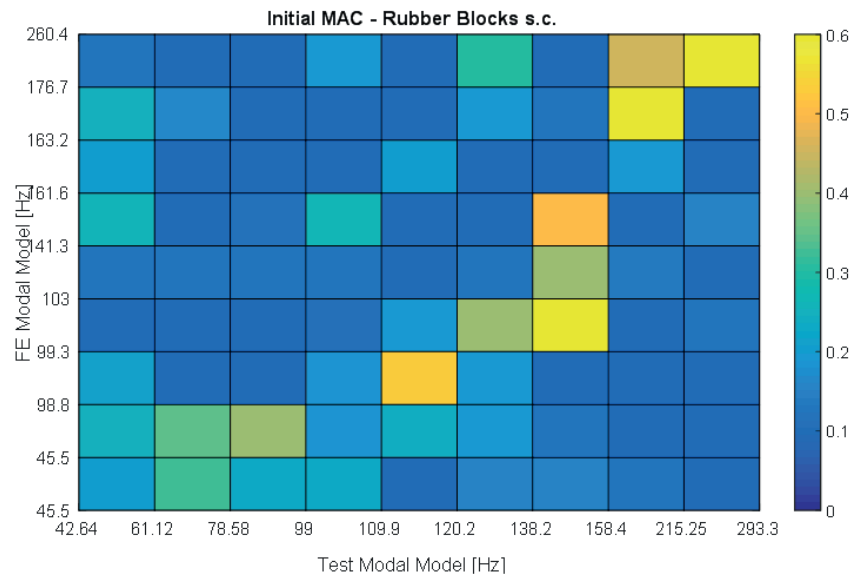

Fig. 7. Initial MAC matrix for the supporting structure founded on rubber blocks.

What is noteworthy in Fig. 7 is the absence of the experimentally recorded $4^{\text {th }}$ vibration mode in the modal FEM set. In this mode, the tripod behaves as a rigid body and performs a reciprocating motion along the vertical axis. None of the examined configurations of FEM model parameters obtained during the iterative procedure indicated the appearance of this mode. At the same time, the obtained MAC values are relatively small - the maximum value obtained during the tests was equal to 0.67 . All this lead to a conclusion that the created FEM model does not model properly dynamic characteristics of the real structure. 


\section{DOE AND RSM METHOD BASED ANALYSIS}

The effect of element stiffness on the natural vibration frequency in the FEM model was analysed using the DOE (Design of Experiment) method. This method makes it possible to trace the effect of input value changes on the output values, by introducing a discrete set of input values in which more than one parameter can be changed. The calculations were performed on high-performance computers at the Academic Computer Centre TASK in Gdansk, making use of the software Noesis Optimus 10.13 and MSC.Nastran.

Due to a significant effect of vertical flexible element stiffness changes on the results of calculations, the variability range of this parameter was assumed within a narrow interval, unlike the transverse stiffness variability range.

The DOE method based modelling process consisted in creating: the source batch file (bushing_DOE.dat), the source output file (bushing_doe.f06), the input parameter vector - with indicating the place of occurrence of the required parameters in the file (InputArrayl - 9 stiffnesses), and the output parameter vector - with indicating the place of occurrence of the required parameters in the file (Frequen - 15 frequencies). Moreover, the action which allowed to generate the output file from the input file (initiating starting command for the code MSC.Nastran) and mutual relations between the above objects were to be defined, Fig. 8 .

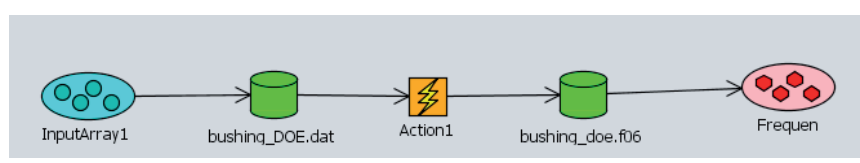

Fig. 8. Scheme of data use in the code Optimus.

The nominal values of the parameters, their variability ranges, and the used nomenclature of input/output parameters are given in Fig. 9 and Fig. 10. The stiffnesses BK1, BK4, BK5 of the flexible element (EP) are marked, respectively, using the following indices: 1, 2, 3 - stiffnesses along the $\mathrm{x}$-axis direction (according to the model coordinate system); 2, 5, 8 - stiffnesses along the y-axis direction, and 3, 6, 9 - stiffnesses along the vertical axis direction.

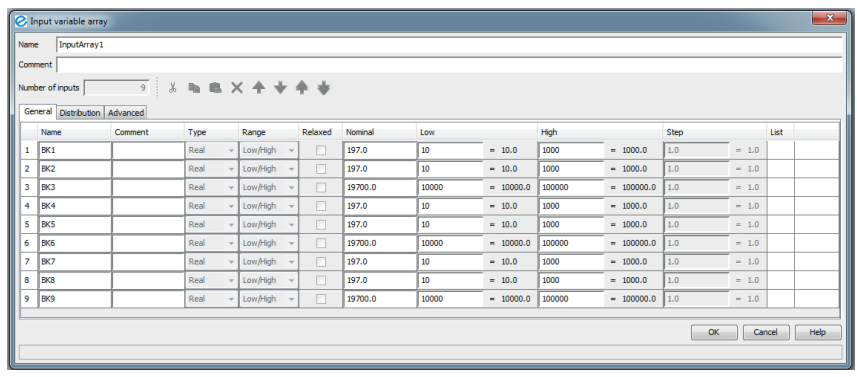

Fig. 9. Definition of the input parameter vector.

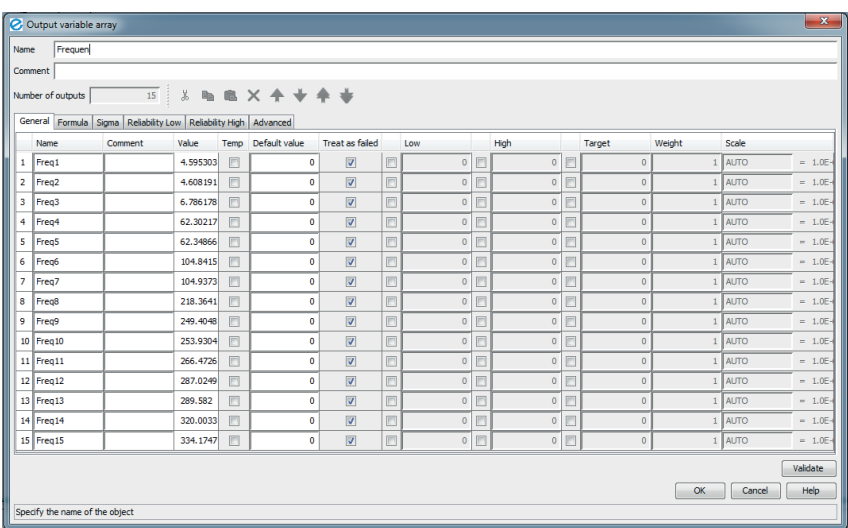

Fig.10. Definition of the output parameter vector.

The applied approach made use of the $2^{\text {nd }}$ order model and the $3^{\text {rd }}$ level full factorial DOE method. Taking into consideration all possible combinations of numerical model parameters, the total number of experiments was 19683 , Fig. 11.

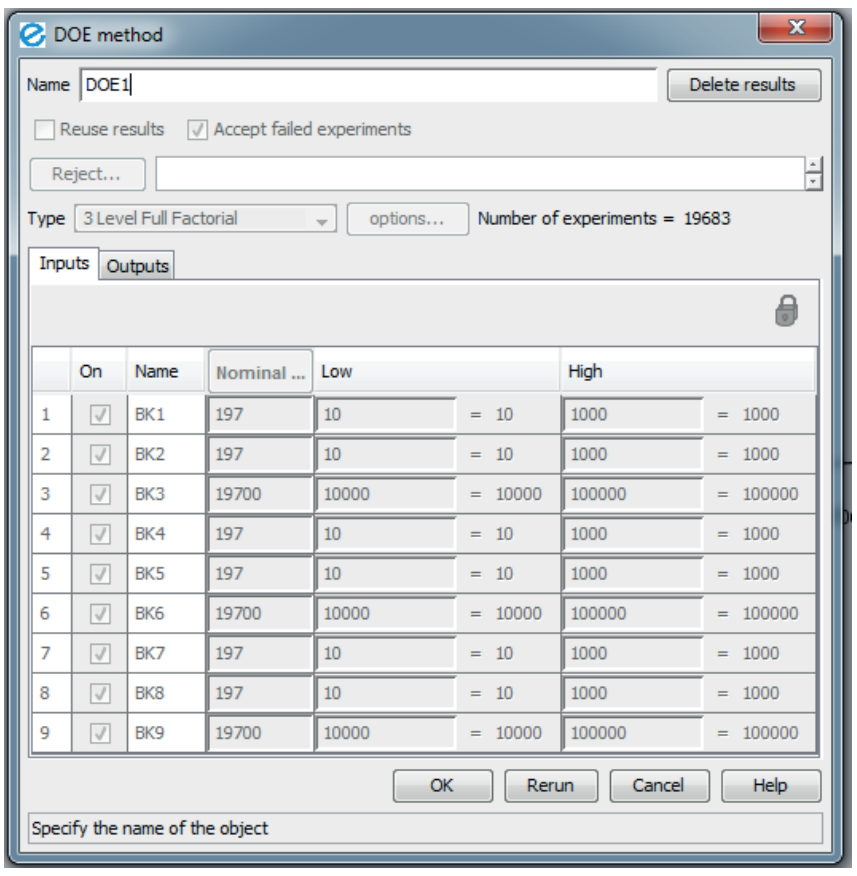

Fig. 11. Definition of the used $3^{\text {rd }}$ Level Full Factorial method.

Due to a large number of data and the dependence of the analysed state on several parameters (the $2^{\text {nd }}$ order model), a convenient tool for analysing the obtained results is the response surface model (RSM) method. This method enables 3D presentation of results of a numerical experiment, and displays system response changes in the form of surfaces for two fixed parameters. Figures 12, 13, and 14 show sample changes of the $3^{\text {rd }}$ natural vibration frequency (corresponding to the vibration along the vertical axis of the object) for constant values of stiffnesses EP1 and EP2 in the vertical direction and changes of the remaining parameters. The 
analysed results reveal small sensitivity of the tripod's natural vibration frequency to stiffness changes in the direction perpendicular to the vertical axis of the object. The only stiffness which affects this frequency to a relatively great extent is the stiffness EP3 in the vertical axis direction. Decreasing the horizontal stiffness EP makes the tripod vibrate as a solid body, while increasing the stiffness in those directions leads to the appearance of frequencies which were not recorded experimentally (with respect to both, the value and the eigenvector). This may testify to limited possibilities to reduce the tripod motion in the directions on its foundation plane. Moreover, analysing the scatter plots of correlations between the values calculated using the DOE method and those estimated by the model, we can see that the noncompliance range is unacceptably large and, consequently, the parameter variability ranges should be substantially decreased. However, this would lead to even smaller effect of model stiffnesses in the $\mathrm{x}$ - and $\mathrm{y}$-axis direction on system vibration frequency changes. Figure 15 shows a sample scatter plot for the $3^{\text {rd }}$ frequency. The stiffness in the vertical direction is definitely too small, and it differs by as much as 12 times from that recorded experimentally, which testifies that the stiffness of rubber blocks cannot be determined based only on the mass of the system and the resonance frequency (even if the mode represents the undeformed tripod), or on the force method.
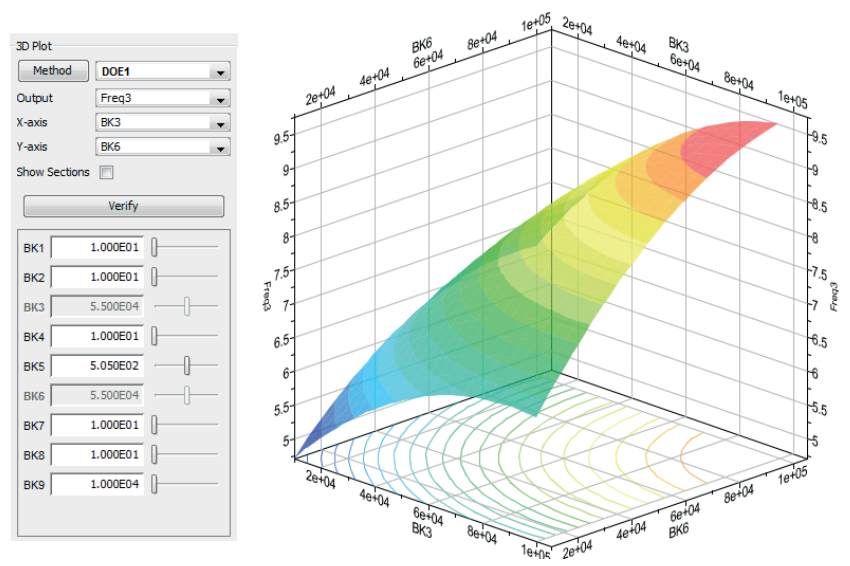

Fig. 12: Natural vibration frequency changes for constant vertical stiffnesses $B K 3$ and BK6 (the remaining stiffnesses at the minimum level).
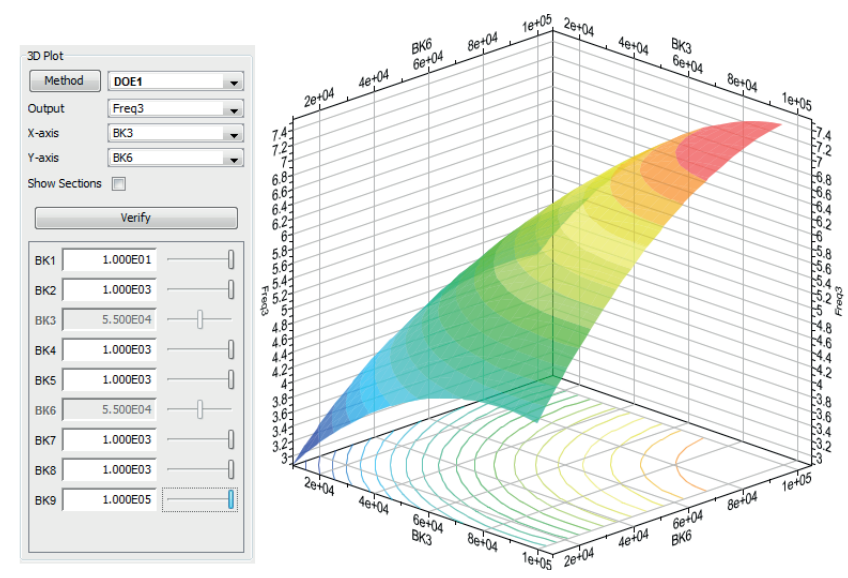

Fig. 13. Natural vibration frequency changes for constant vertical stiffnesses $B K 3$ and BK6 (the remaining stiffnesses at the maximum level).
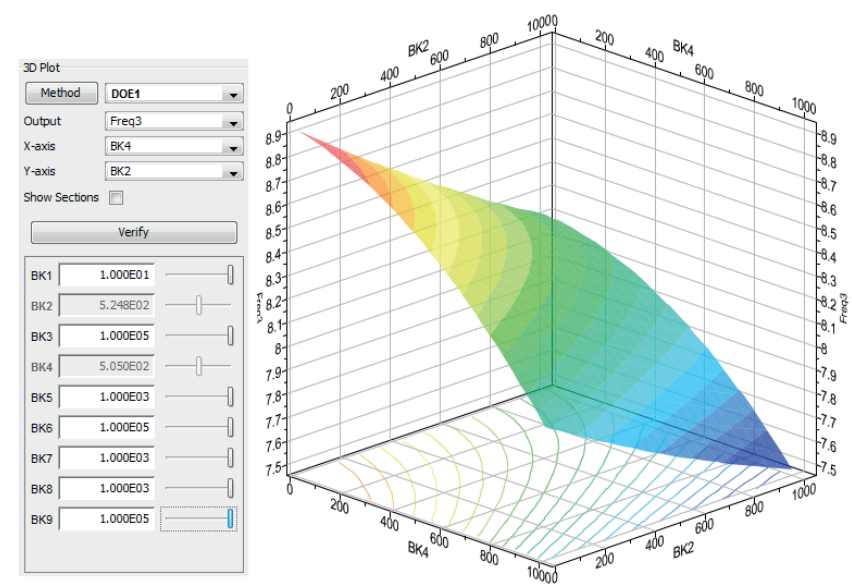

Fig.14. Natural vibration frequency changes for maximal vertical stiffness values.

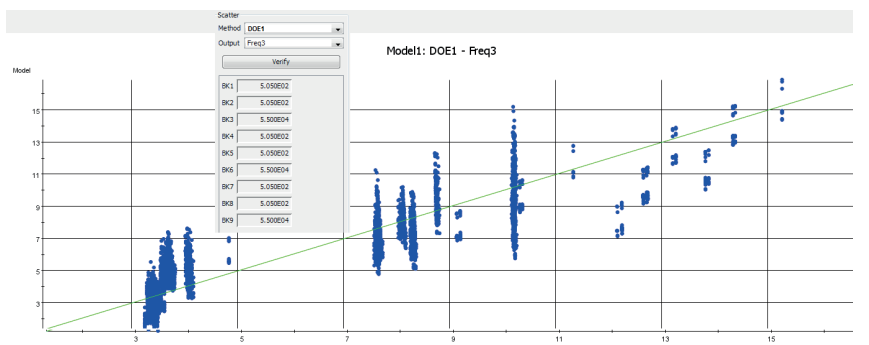

Fig. 15. $3^{\text {rd }}$ natural vibration frequency for maximal vertical stiffness values. 


\section{CONCLUSIONS}

The test model and the FEM model, which initially revealed relatively good correlation, became very difficult to correlate, and thus to identify, after changing the boundary conditions from the free-free configuration to the elastic support configuration. Despite resignation from the use of standard boundary condition, which consisted in reducing the degrees of freedom at nodes, and replacing it by the support in the form of flexible elements, the examined structures exhibited very little similarity to each other in both models. This effect was likely to be caused by the lack of information on, or impossibility to determine, parameters describing quantitatively the structural properties of the supporting structure. Despite tuning the flexible elements with the aid of the natural vibration mode which was very similar to the behaviour of the harmonic oscillator, the attempt to assess correctly the stiffness of flexible tripod elements in the vertical direction ended without success. The resultant vibration frequency of the $3^{\text {rd }}$ natural mode obtained in the numerical experiments oscillated about $10 \mathrm{~Hz}$ (at the required value of $120 \mathrm{~Hz}$ ). The statistical analysis, performed with the aid of DOE and RSM methods, allowed to notice some trends in structural responses of the virtual model, as a result of changing input parameters. Based on the above observations, negligibly small effect of the analysed parameters on the $3^{\text {rd }}$ values and modes of other stiffnesses than that in the vertical direction was identified. Moreover, the DOE results indicate a possible direction of search for support parameters which would better reflect the physics of the examined phenomenon. The stiffness values are to be searched at much higher levels than the estimated (nominal) vertical stiffness of the blocks $(19700 \mathrm{~N} / \mathrm{m})$ and, on the other hand, much below the maximal transverse stiffnesses $(1000 \mathrm{~N} / \mathrm{m})$. The analysis of this type can also indicate, in general, whether the assumed range of the searched values is narrow enough to avoid excessive errors.

The above remarks can be important indication for SHM techniques, for instance. In the case of real offshore wind turbines founded on the seabed, an issue of high importance will be correct identification of properties of the seabedfoundation structure, especially in the case of high gradients of geological properties in the area occupied by the wind farm.

The presented sample case was relatively easy to analyse, due to the earlier obtained compliance between the test model (in the free-free support configuration) and the FEM model. The inconsistency which appeared after changing the support configuration was immediately diagnosed as the effect of the applied form of support conditions which limited the search area to only 9 parameters. Perhaps, the remaining structural parameters, solely related with the tripod structure, should be additionally included to the set of search parameters. However, this would make their analysis extremely difficult, if not impossible at all.

\section{BIBLIOGRAPHY}

1. Kahsin M., Luczak, M., Peeters, B.: Use and assessment of preliminary FE model results within testing process of offshore wind turbine supporting structure, EURODYN 2014: IX INTERNATIONAL CONFERENCE ON STRUCTURAL DYNAMICS Book Series: EURODYNInternational Conference on Structural Dynamics, pp. 3659-3666 Published: 2014.

2. Kahsin, M., Luczak, M.: Numerical Model Quality Assessment of Offshore Wind Turbine Supporting Structure Based on Experimental Data, STRUCTURAL HEALTH MONITORING 2015: SYSTEM RELIABILITY FOR VERIFICATION AND IMPLEMENTATION, VOLS. 1 AND 2 Book Series: Structural Health Monitoring, pp. 2817-2824 Published: 2015.

3. Kozicki J., Tejchman-Konarzewski A., Mühlhaus H.: Discrete simulations of a triaxial compression test for sand by DEM. INTERNATIONAL JOURNAL FOR NUMERICAL AND ANALYTICAL METHODS IN GEOMECHANICS, iss. 18 (2014), pp.1923-1952.

4. Deja M., Siemiątkowski M.: Feature-based generation of machining process plans for optimised parts manufacture// JOURNAL OF INTELLIGENT MANUFACTURING. -Vol. 24, iss. 4 (2013), pp. 831-846.

5. Niklas K., Kozak J.: Experimental investigation of SteelConcrete-Polymer composite barrier for the ship internal tank construction// OCEAN ENGINEERING. -Vol. 111, (2016), pp. 449-460.

6. Ambroziak A., Kłosowski P.: Mechanical testing of technical woven fabrics. JOURNAL OF REINFORCED PLASTICS AND COMPOSITES. Vol. 32, Iss. 10 (2013), pp.726-739.

7. Ambroziak A., Kłosowski P.: Mechanical properties for preliminary design of structures made from PVC coated fabric. CONSTRUCTION AND BUILDING MATERIALS. -Vol. 50, (2014), pp.74-81.

8. Burdziakowski P., Janowski A., Kholodkov A., Matysik K., Matysik M., Przyborski M., Szulwic J., Tysiąc P., Wojtowicz A.: MARITIME LASER SCANNING AS THE SOURCE FOR SPATIAL DATA// Polish Maritime Research. -Vol. 22, Iss. 4(88) (2015), pp. 9-14.

9. Di Lorenzo E. Petrone G., Manzat S., et al.: STRUCTURAL HEALTH MONITORING-AN INTERNATIONAL JOURNAL Volume 15, Issue: 3, pp. 289-301 Published: MAY 2016.

10. El-KafafyM., Peeters B., Guillaume P., et al.: MECHANICAL SYSTEMS AND SIGNAL PROCESSING Volume: 72-73, pp. 567-589 Published: MAY 2016. 
11. Litwin W., Olszewski A.: Water-Lubricated Sintered Bronze Journal Bearings-Theoretical and Experimental Research// TRIBOLOGY TRANSACTIONS. -Vol. 57, no. 1 (2014), pp.114-122.

12. Price, D. C.; Clark, M. A., Barsdell, B. R., et al.: Optimizing performance-per-watt on GPUs in high performance computing, COMPUTER SCIENCE-RESEARCH AND DEVELOPMENT Volume 31, Issue 4, pp.185-193 Published: NOV 2016.

13. Locharla G., Rao K., Sudeendra K., Mahapatra K., et al.: Implementation of MIMO data reordering and scheduling methodologies for eight-parallel variable length multi-path delay commutator FFT/IFFT, IET COMPUTERS AND DIGITAL TECHNIQUES Volume 10, Issue: 5, pp. 215-225 Published: SEP 2016.

14. Iwicki P., Tejchman A., Chróścielewski J.: Dynamic FE simulations of buckling process in thin-walled cylindrical metal silos. THIN-WALLED STRUCTURES. Vol. 84 (2014), pp.344-359.

15. Górski J., Mikulski T., Oziębło M., Winkelmann K.: Effect of geometric imperfections on aluminium silo capacities// STAHLBAU. -Vol. 84, iss. 1 (2015), pp.52-57.

16. Dymarski C., Dymarski P., Zywicki, J.: DESIGN AND STRENGTH CALCULATIONS OF THE TRIPOD SUPPORT STRUCTURE FOR OFFSHORE POWER PLANT, POLISH MARITIME RESEARCH Volume: 22, Issue: 1, pp. 36-46, Published: JAN 2015.

17. Dymarski P., Ciba E., Marcinkowski, T.: EFFECTIVE METHOD FOR DETERMINING ENVIRONMENTAL LOADS ON SUPPORTING STRUCTURES FOR OFFSHORE WIND TURBINES, POLISH MARITIME RESEARCH, Volume 23, Issue 1, pp. 52-60, Published: JAN 2016.

18. Grelowska G., Kozaczka E.: Sounding of Layered Marine Bottom - Model Investigations// ACTA PHYSICA POLONICA A. -Vol. 118, nr. no. 1 (2010), pp. 66-70.

19. Grelowska G., Kozaczka E., Kozaczka S., Szymczak W.: Sea bottom structure investigation by means of acoustic methods// POLISH JOURNAL OF ENVIRONMENTAL STUDIES. -Vol. 19, no. 4A (2010), pp. 35-38.

20. Heylen, W., Lammens, S., Sas, P.: Modal analysis theory and testing, Katholieke Universiteit Leuven, Belgium, 2009.

21. Pannerselvam, R.: Design and Analysis of Experiments, ISBN 978-81-203-4499-0, New Dehli, India, 2012.

\section{CONTACT WITH THE AUTHOR}

\author{
Maciej Kahsin
}

Gdansk University of Technology

Faculty of Ocean Engineering and Ship Technology

11/12 Narutowicza St. 80 - 233 Gdańsk

Poland; 